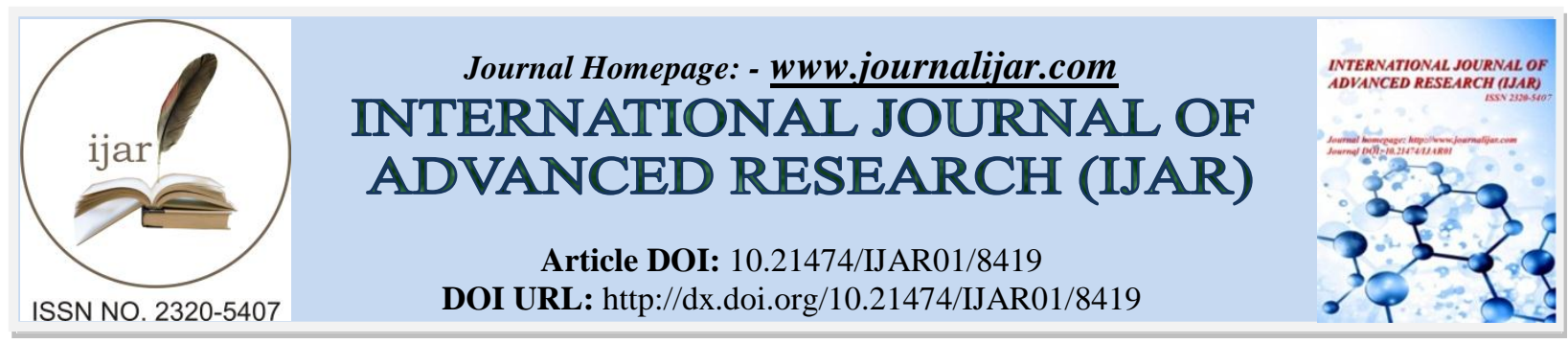

RESEARCH ARTICLE

\title{
VERSATILITY OF TIME-VARYING AMPLITUDE METHOD IN HARMONIC ANALYSIS OF DISCRETE DATA.
}

\author{
Uchenwa linus okafor, O.Oladejo, D.T.Chinyo and C.O.Uwa.
}

Faculty of Science,Nigerian Defence Academy, Kaduna.

\section{Manuscript Info}

Manuscript History

Received: 16 November 2018

Final Accepted: 18 December 2018

Published: January 2019

Key words:-

Amplitude, cosine wave, harmonic

analysis, time-varying.

\begin{abstract}
This paper proposes a method that overcomes the problem of the amplitude not being zero at the starting time .when the Cosine waveform is used in Harmonic analysis. The paper employs the method of time-varying amplitude method to get a satisfactory answer to this nagging issue of the amplitude having a value different than zero when the motion has not started for discrete data. Models obtained using the time-varying amplitude method have shown to produce better results than those from the constant amplitude model when the traditional time-invariant Fourier method is employed in Fourier analysis. The method is also flexible in the sense that it can be used to convert a decaying amplitude to a growing one and vice versa and at the same time produces amplitudes that will match oscillations whose amplitudes change with time. Using the time-varying amplitude method reduced the Sum of squares of errors of the constant amplitude model by about $56 \%$ and increased the amplitude by over $91 \%$, and more weights are giving to the recent data like in the smoothing methods .Besides, the method has reduced the effect of spurious correlation in time series.
\end{abstract}

Copy Right, IJAR, 2018,. All rights reserved.

\section{Introduction:-}

Fourier analysis of nonstationary time series data has always employed the use of the constant amplitude model .This paper presents the versatility of the time-varying Fourier amplitude model advocated by Okafor and Oladejo[8] and well documented by Okafor[9] in answer to issues raised by Cheng[11] on the need to produce models in the frequency domain whose amplitudes could be time-dependent, this is in line with the observation of Baghzouz et al[1] that field measurements clearly indicate that voltage and current harmonics are time-variant due to continual changes in system configuration and load conditions. Gardner [7] has explained that spectral analysis is expected to be useful for time-variant phenomenon as long as the time-variant is sufficiently slow. In real life situations there are instruments modelled using time-invariant Fourier amplitude models that could have been modeled instead with the time-variant Fourier amplitude so that Hooks' law of proportionality will be obeyed. The use of time-dependent Fourier amplitude in electrical instruments will help in reducing cases of heating elements of pressing iron burning up before the expected time, fuses blowing up as a result of high voltage supply, piston and rings of motor cars burning due to prolong usage on journeys and firing pins of fighting arms breaking up after extended time of firing them.

Corresponding Author:-Uchenwa Linus Okafor.

Address:-Mathematics Department' Nigerian Defence Academy, Kaduna. 
But Bloomfield [3] had earlier said that there is no sinusoid model that could match oscillations whose amplitudes grow with time. Modeling of nonstationary time series data is known to have produced unsatisfactory results, that long time ago, Yule [12] asked: "Why do we have spurious regression?"

Ossietzky [10] stated that Fourier series is made up of two parts, which are ;analysis and synthesis and said that the necessary calculations of the parameters which is made up of the wavelength, phase and frequency, of the harmonic signal which is periodic is called Fourier analysis or harmonic analysis or harmonic expansion. Harmonic analysis according to Bird [2] is the process of resolving periodic wave forms into a series of sinusoidal components of ascending of frequency. He further mentioned that by adding the instantaneous values of the fundamental and progressive frequency at a given time instant, the shape of the complex wave form is built up.

\section{Statement of the problem and the aim of the study.}

Various authors have shown many ways of transforming nonstationary data so as to reduce the effect of autocorrelation of the residuals, but, Bowerman et al [4] given the disadvantages of using a transformed data in forecasting as that will mean that there is linear increasing seasonal variation in the original data. It is the need to overcome deforming the data structure caused by data transformation that motivated the search for an alternative method as proposed here.The aim of this paper is to demonstrate how time-varying Fourier amplitude model has overcome the short comings of the traditional constant Fourier amplitude model.

\section{Data and materials used.}

The data used in this paper is the Classical Air Line Passenger's Data of Box and Jenkins [5], and the data analysis was done using the software: "The Number Cruncher Statistical System NCSS ${ }^{12 "}$, developed by Chris [6].

\section{Mathematical Formulation of the Time- Dependent Fourier Amplitude Model}

In the classical or time-invariant Fourier amplitude model, the Fourier series, is represented as a function that is either continuous or discrete process with fundamental harmonic containing terms of the forms shown in equations (1a and $1 \mathrm{~b})$

$$
\begin{aligned}
& f(x)=a_{0}+\sum_{n=1}^{\infty}\left(a_{n} \cos \frac{n \pi x}{L}+b_{n} \sin \frac{n \pi x}{L}\right) \\
& f(x)=a_{0}+\sum_{k=1}^{L / 2}\left(\left(a_{k} * \operatorname{Cos}(\text { 回 } k t)+b_{k} * \sin (\text { 回 } k t)\right)\right.
\end{aligned}
$$

Where

$$
\mathrm{k}=\left\{1,2, \ldots \frac{\mathrm{L}}{2}\right\}
$$

$\mathrm{L}=$ Seasonal length, which is 12 for monthly data, 4 for quarterly data,etc.

$$
\mathrm{a}_{\mathrm{k}}=\text { Cosine component of the amplitude and, }
$$

$\mathrm{b}_{\mathrm{k}}=$ sine component of the amplitude

$$
\mathrm{A}=\sqrt{ }\left(a^{2}+b^{2}\right)
$$$$
\text { ? }{ }_{\mathrm{k}}=\frac{2 \pi}{L}, \mathrm{k}^{\text {th }} \text { frequency }
$$$$
\pi=\frac{22}{7}
$$

$\mathrm{t}=1,2,3, \ldots, \mathrm{N}, \mathrm{N}$ is the number of data points .

In time- dependent Fourier amplitude model, the Fourier series shown in equation (1b), will now appear as shown in equation (3) below:

$$
f(x)=a_{0}+\sum_{k=1}^{L / 2} \frac{t}{N} *\left(\left(a_{k} * \operatorname{Cos}\left(\square_{k} t\right)+b_{k} * \sin \left(\square_{k} t\right)\right)\right.
$$

When a time series is not stationary, there is a trend, equations (7) and (9) will assume the forms shown (4a) and (4b) respectively

$$
\begin{aligned}
& \mathrm{f}(x)=\sum_{t=0}^{p} a_{t} b^{t}+\sum_{k=1}^{L / 2}\left(\left(a_{k} * \operatorname{Cos}\left(\mathrm{Q}_{k} t\right)+b_{k} * \sin \left(\mathrm{Q}_{k} t\right)\right)\right. \\
& \mathrm{f}(x)=\sum_{t=0}^{p} a_{t} b^{t}+\sum_{k=1}^{L / 2} \frac{t}{N} *\left(\left(a_{k} * \operatorname{Cos}\left(\mathrm{Q}_{k} t\right)+b_{k} * \sin \left(\mathrm{Q}_{k} t\right)\right)\right.
\end{aligned}
$$

\section{Data Analysis and Results:-}

Fig.1. shows the result of the amplitudes obtained for the Time-Dependent Fourier Amplitude Model (TDFAM) and Time-Independent Fourier Amplitude Model (TIFAM). 


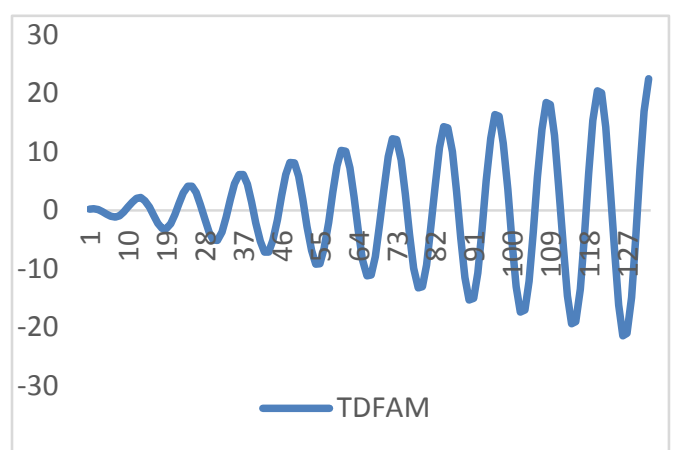

Fig 1A:-Plot of Amplitudes of TDFAM

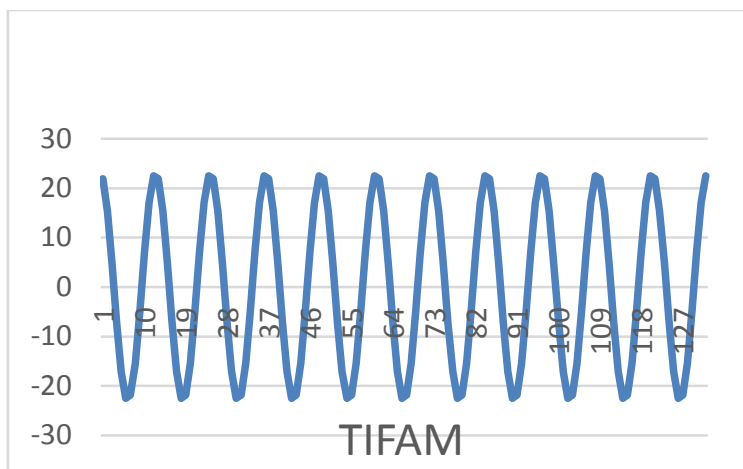

Fig 1B:-Plot of Amplitudes of TIFAM

The plots errors for the Air Line Passengers data using the method of TDFAM and TIFAM are displayed in Fig.2B and Fig.2A.

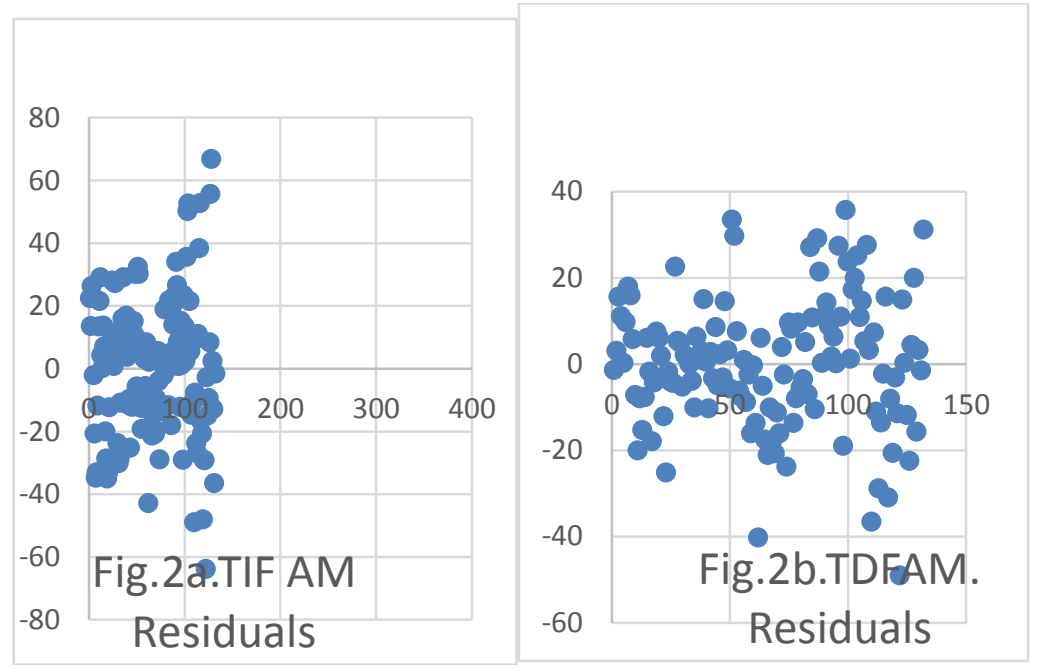

Summary Of Results:-

Table 1,is a summary of the performances of the two models of TIFAM and TDFAM.

Table 1:-Model performances for TIFAM and TDFAM

\begin{tabular}{|l|l|l|l|l|}
\hline Model & SSE & R-Squared & $\begin{array}{l}\text { Amplitude of First } \\
\text { Harmonic(A1) }\end{array}$ & $\begin{array}{l}\text { Amplitude of Second } \\
\text { Harmonic(A2) }\end{array}$ \\
\hline TIFAM & $\mathbf{6 6 9 1 8 . 9 1}$ & $\mathbf{9 5 . 5 3 \%}$ & $\mathbf{4 1 . 8 6}$ & $\mathbf{2 3 . 8 2}$ \\
\hline TDFAM & $\mathbf{2 9 7 5 7 . 0 4}$ & $\mathbf{9 8 . 0 2 \%}$ & $\mathbf{8 0 . 2 3}$ & $\mathbf{4 2 . 8 6}$ \\
\hline & $\begin{array}{l}\text { Reduction in } \\
\text { SSE=55.53\% }\end{array}$ & & $\begin{array}{l}\text { \% Increase in First } \\
\text { Amplitude=91.66 }\end{array}$ & $\begin{array}{l}\text { \% Increase in Second } \\
\text { Amplitude=979.931.66 }\end{array}$ \\
\hline
\end{tabular}

\section{References:-}

1. Baghazou,Y, Y, R.E Morrison, P.F. Ribeiro and C.A. Duque (2001); Time-varying Waveforms/Distortions Power Systems. John Wiley and Sons

2. Bird John (2000) Higher Engineering Mathematics.Newness,An Imprint of Elsevier

3. Bloomfield, P.(1998);Fourier Analysis of Time Series .Second Edition. I Wiley and Sons Inc.

4. Bowerman,B.L,Koehler A.B and Pack D.J(1990) Forecasting Time Series with increasing Seasonal Variations, Journal of Forecasting,No.5,Vol9,419-436,1990

5. Box,G.E.P., and G.M, Jenkins(1976) ; Time Series Forecasting and Control.Englewood Cliffs,NJ:Printice Hall

6. Chris Hintz (2017); Number Cruncher Statistical software(NCSS ${ }^{12}$ )

7. Gardner, A. William(1998); Statistical Spectral Analysis. Printice Hall 
8. Okafor, U.L and Oladejo,M.O (2013);"Another Look at Fourier Coefficients, Forecasting Nonstationary Time Series Using Time-Dependent Fourier Coefficients." Journal of Computing,Communication and Instrumentation Engineering (IJCCIE),Vol.1,Issue1 (2014), pp186-92

9. U.L,Okafor (2015);Discrete Approximation of Nonstationary Sequences by Time-Weighted Fourier Amplitude. PhD Thesis, Nigerian Defence Academy,Kaduna,Nigeria

10. C.V,Ossiotzko (2005); Fourier Analysis Module. Introductory Laboratory Course Physcis.University of Oldenber

11. Yang Cheng(1997);Bayesian Time Series: Financial Models and Spectral Analysis,PhD Dissertation.Duke University.

12. G.U. Yule (1926); Why Do We Sometimes Get Nonse Correlation Between Time Series?. A Study in Sampling and the Nature of Time Series.Journal of Royal Statistical Society.Vol 89,1926,pp1-44. 